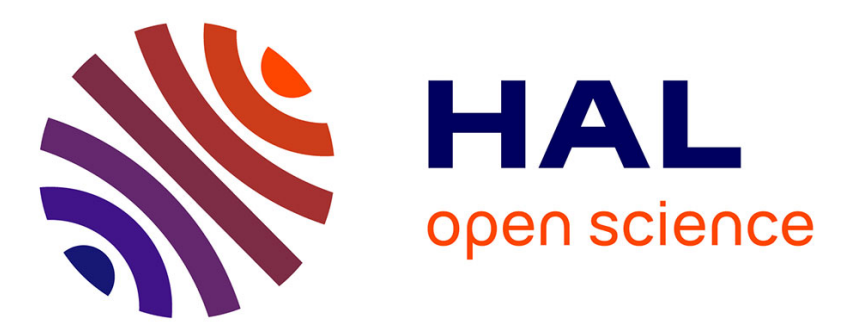

\title{
Effect of the SH3-SH2 domain linker sequence on the structure of Hck kinase
}

\author{
Heike Meiselbach, Heinrich Sticht
}

\section{To cite this version:}

Heike Meiselbach, Heinrich Sticht. Effect of the SH3-SH2 domain linker sequence on the structure of Hck kinase. Journal of Molecular Modeling, 2010, 17 (8), pp.1927-1934. 10.1007/s00894-010-0897-z . hal-00645110

\section{HAL Id: hal-00645110 https://hal.science/hal-00645110}

Submitted on 26 Nov 2011

HAL is a multi-disciplinary open access archive for the deposit and dissemination of scientific research documents, whether they are published or not. The documents may come from teaching and research institutions in France or abroad, or from public or private research centers.
L'archive ouverte pluridisciplinaire HAL, est destinée au dépôt et à la diffusion de documents scientifiques de niveau recherche, publiés ou non, émanant des établissements d'enseignement et de recherche français ou étrangers, des laboratoires publics ou privés. 


\title{
Effect of the SH3-SH2 domain linker sequence on the structure of Hck kinase
}

Received: 30.06.2010 / Accepted: 23.10.2010

Heike Meiselbach and Heinrich Sticht ${ }^{凶}$

Bioinformatik, Institut für Biochemie, Friedrich-Alexander-Universität, Erlangen-Nürnberg, Fahrstraße 17, D-91054 Erlangen, Germany

${ }^{\circledR}$ Tel.: +49 - 9131 / 85 24614; Fax: +49 - 9131 / 85 22485; E-Mail: h.sticht@ biochem.unierlangen.de

\begin{abstract}
The coordination of activity in biological systems requires the existence of different signal transduction pathways that interact with one another and must be precisely regulated. The Src-family tyrosine kinases, which are found in many signaling pathways, differ in their physiological function despite their high overall structural similarity. In this context, the differences in the SH3-SH2 domain linkers might play a role for differential regulation, but the structural consequences of linker sequence are yet poorly understood. We have therefore performed comparative molecular dynamics simulations of wildtype Hck and of a mutant Hck, in which the SH3-SH2 domain linker is replaced by the sequence from the homologous kinase Lck. The simulations reveal that linker replacement does not only affect the orientation of the SH3 domain itself, but also leads to an alternative conformation of the activation segment in the Hck kinase domain. The sequence of the SH3-SH2 domain linker thus exerts a remote effect on the active site geometry and might therefore play a role in modulating the structure of the inactive kinase or for the fine-tuning of the activation process itself.
\end{abstract}

Keywords Src-family kinases $\cdot \mathrm{SH} 3 \cdot \mathrm{SH} 2 \cdot$ Molecular dynamics simulations $\cdot$ Domain motions 


\section{Introduction}

The Src family of non-receptor tyrosine kinases to date comprises nine members (Src, Fyn, Lck, Hck, Yes, Fgr, Yrk, Blk, and Lyn) which play critical roles in eukaryotic signal pathways that control a diverse array of processes such as cell growth, differentiation, activation and transformation [1-3]. These proteins have a common molecular architecture that includes five distinct regions [4, 5]: a unique $\mathrm{N}$-terminal region with sequences for lipid attachment, the regulatory $\mathrm{SH} 3$ and $\mathrm{SH} 2$ domains and a kinase domain, followed by a negative regulatory C-terminal tail (Fig. 1b). The $\mathrm{SH} 2$ and $\mathrm{SH} 3$ domains bind specific phosphotyrosine and proline-rich motifs, respectively. The catalytic domain consists of two lobes, which form a cleft that serves as a docking site for ATP and other substrates representing the active site of the kinase.

The crystal structures of the inactive ('closed') forms of c-Src [6-8] and Hck [9, 10] reveal that intramolecular interactions involving the $\mathrm{SH} 2$ and $\mathrm{SH} 3$ domains are essential for suppression of kinase activity despite being far away from the active site. In fact, these regulatory domains are bound to the distal side of the catalytic domain, restricting its conformational flexibility to hinder productive ATP binding. The SH3 domain is docked to the $\mathrm{N}$-terminal lobe of the kinase domain via a proline-containing motif in the SH2-kinase linker (Fig. 1b).

Activation of Src-family kinases (SFKs) requires the disruption of the intramolecular interactions, the dephosphorylation of the C-terminal tail by phosphatases, or the binding of high-affinity ligands to the $\mathrm{SH} 2$ or the SH3 domain [9-12]. Additionally, the active conformation becomes stabilized upon autophosphorylation of Tyr416 (in Src) in the activation segment and is required for maximal kinase activity [13, 14]. In this case, the phosphorylated activation segment, which contains the highly conserved aspartatephenylalanine-glycine (DFG) motif, becomes less ordered and moves out of the active site, thereby allowing substrate access [15].

An additional feature, which turned out to be important for the activation process, is the sequence of the linker that connects the SH3 and SH2 domain. In wildtype Src and Hck, a short rigid linker joins the regulatory SH3 and SH2 domains and leads to dynamic coupling of the two domains in the closed conformation, thereby forming a stiff clamp [16, 17]. Computational studies and site-directed mutagenesis experiments have shown that the 
disruption of the structural properties of the rigid linker by introduction of glycine mutations reduces the strength of the clamp and facilitates activation of the kinase [17].

In Hck and most other SFKs the connecting linker stabilizes the SH3-SH2 domain orientation by a salt-bridge between a conserved glutamate of the linker (E147 in Hck) and a lysine (K104 in Hck) of the SH3 domain. In the homologous kinase Lck, E147 is replaced by proline and therefore the salt-bridge cannot be formed. Accordingly, the isolated Lck SH3-SH2 domain pair shows an ill-defined domain orientation in NMR-spectroscopic studies [18, 19]. The effect of the Lck linker sequence on the intact kinase, however, is yet poorly understood due to the lack of an intact Lck crystal structure containing both regulatory and kinase domains.

To assess whether the differences in linker sequence also affect the structure of inactive SFKs, we have investigated the effect of linker replacement using Hck as a model system. Comparative molecular dynamics simulations were performed for wildtype Hck and for a mutant Hck (Hck*), in which the SH3-SH2 domain linker was replaced by the respective sequence from Lck. To address the effect of the inhibitor PP1 on kinase dynamics, simulations were performed in the presence and absence of PP1 totalling up to four systems studied. Our results show that an altered linker sequence does not only result in local changes, but also has a remote effect on the geometry of the active site.

\section{Materials and methods}

\section{Preparation of starting structures}

The crystal structures of inactive Hck complexed with the nucleoside analog PP1 (Protein Data Bank ID 1QCF, [10]), was used to generate the starting structures. For consistency, the sequence numbering from entry $1 \mathrm{QCF}$ was also adapted in the present work. To obtain the model of mutant Hck (termed Hck*), the wildtype SH3-SH2 linker sequence ( ${ }_{140} \mathrm{~V}$-D-S-L-ET-E-E ${ }_{147}$ ) was replaced with the linker sequence form Lck (A-N-S-L-E-P-E-P) (Fig. 1a) using the Sybyl 7 [20]. Inspection of the model revealed no steric clashed indicating that the Lcklinker sequence can be readily accommodated in the Hck scaffold. The systems Hck and Hck* were simulated each with and without inhibitor PP1. 
The force field parameters for PP1, which are not available in the AMBER package, were obtained as follows: The initial coordinates of PP1 were extracted from the 1QCF pdb file. ArgusLab [21] was utilized to add missing hydrogen atoms. Then, the structure was subjected to two consecutive geometry optimizations with Gaussian03 [22] using the ab initio methods HF/MIDI!, and HF/6-31G(d). For all quantum mechanical geometry optimizations the stationary points found were ensured to be true minima by the calculation of the vibrational frequencies. The atomic charges for PP1 were then obtained following the established procedure $[23,24]$ by fitting the charges to the $\mathrm{HF} / 6-31 \mathrm{G}(\mathrm{d})$ computed electrostatic potential using the Antechamber tool from the AMBER program suite.

\section{Molecular dynamics (MD) simulations}

All MD simulations were performed using the PMEMD module of AMBER $8.0[25,26]$ with the parm99 force field [27, 28]. For the organic compound PP1 the general AMBER force field (gaff) [29] was used. The parameters for the phosphotyrosine present in the C-terminal kinase tail were assigned according to Homeyer et al. [30].

An appropriate number of $\mathrm{Na}+$ counter ions was added to neutralize the system and afterwards the molecules were solvated in a box of water using the TIP3P water model [31] with at least $10 \AA$ of water around every atom of the solute. All structures were minimized in a three-step procedure by using the SANDER module of AMBER following a previously established protocol [32].

After energy minimization, the system was equilibrated for $0.1 \mathrm{~ns}$, raising the temperature gradually to $298 \mathrm{~K}$ by coupling to a temperature bath with a time constant of $0.2 \mathrm{ps}$, as described by Berendsen [33]. Subsequently, 30-ns MD simulations with standard NPT conditions were performed for data collection. Classical equations of motion were propagated numerically with a time step of 1 fs. A cutoff distance of $10 \AA$ was used for the non-bonded interactions, and the particle mesh Ewald method [34] was employed to calculate the longrange electrostatic interactions. All bonds involving hydrogen atoms were constrained using the SHAKE procedure [35].

The convergence of temperature, pressure, and energy of the systems, as well as the atomic root mean square deviations of the structure, were used to verify the stability of the systems. 
For the visualization and structural analysis, the programs Sybyl [20], AMBER [25], VMD [36], and DS ViewerPro 6 [37] were used.

\section{Results and discussion}

\section{Influence of the SH3-SH2 linker sequence on the global structure and dynamics of PP1- inhibited Hck}

To determine the effect of the SH3-SH2 linker on the global structure of Src kinases, 30-ns molecular dynamics simulations of wildtype Hck and of Hck with a mutated SH3-SH2 linker (Hck*) were carried out. To address the effect of the inhibitor PP1 bound to the active site, comparative MD simulations were performed for Hck and Hck* with and without PP1 totalling up to four systems studied.

The mobility of the distinct domains and the conformational changes of the kinase structure during the molecular dynamics simulations were first analyzed by monitoring the distances between the centers-of-mass of the different domains. In this analysis, the two subdomains of kinase domain (N-lobe and C-lobe) were considered separately (Fig. 2, right panel).

For the PP1-bound kinases (Fig. 2) the most prominent difference is detected for the distance between the SH3-domain and the N-lobe of the kinase domain. The distance of approximately $29 \AA$ in the start structure of the inhibited Hck* increases up to $32 \AA$ during the simulation (Fig. 2a). Since the only difference between the Hck and Hck* structure is the composition of the SH3-SH2 kinase linker, it is most likely that the linker exchange is responsible for the different behaviour of the Hck* system. Inspection of the distance between the SH3-SH2 linker and the active site reveals that the linker itself also becomes significantly displaced during the MD simulation (Fig. 3).

The rearrangement of the SH3-SH2 linker and of the SH3 domain can also be seen as the most prominent motion in the overlay of the initial and final structure of Hck* (Fig. 4b). In contrast, only minor changes are observed for wildtype Hck during the simulation (Fig. 4a). The changes of the linker orientation in Hck* also affect the adjacent parts of the SH2 domain (in particular helix $\alpha \mathrm{B}$ ), while the $\mathrm{SH} 2$ interface with the C-lobe of the kinase domain is almost unchanged (Fig. 4b). The kinase domain itself is also only marginally affected by the 
linker replacement and shows only minor fluctuations both in the Hck and in the Hck* simulation compared to the starting structure (Fig. 4a, b).

\section{Effect of linker replacement on the uninhibited Hck kinase}

We addressed the question whether linker replacement also has similar structural effects in the absence of the PP1 inhibitor. The MD simulations performed in the absence of PP1 generally reveal fluctuations for both systems indicating that Hck and Hck* need to adapt to the absence of the inhibitor (Fig. 5). Similarly to the PP1-bound simulation, the distance between SH3 domain and N-lobe becomes also larger in the unliganded Hck* compared to Hck (see Fig. 5a vs. 2a). This difference, however, is only in part caused by an increased distance in unliganded Hck* - a second effect is a decrease of the respective distance in wildtype Hck (Fig. 5a). The latter effect might be a consequence of the tight SH3-SH2 clamp in the wildtype, which results in a tighter compression of the active site after removal of the inhibitor (Fig. 6a). Such an effect is not observed for Hck* (Fig. 6b) suggesting that the SH3SH2 clamp on the kinase domain is less strong than in Hck.

The simulations with and without PP1 revealed that the mutation of the linker sequence influences the position of the SH3 domain with respect to the N-lobe. Thus, the identity of the linker sequence does not only affect the structure of isolated $\mathrm{SH} 3-\mathrm{SH} 2$ domain pair as shown in previous studies $[18,19]$, but also the structure of the full-length kinase in its closed conformation. In the next step, we investigated whether linker replacement also has an effect on the geometry of the active site itself.

\section{Effects of the SH3-SH2 linker sequence on the activation segment}

The active site, which is located between the $\mathrm{N}$ - and $\mathrm{C}$-lobe of the kinase domain, contains an activation segment with a highly conserved aspartate-phenylalanine-glycine (DFG) motif. This segment does not only undergo significant structural changes during the activation process itself, but can also adopt at least two distinct conformations in the inactive kinase. This structural feature also plays a critical role for the drug binding properties of tyrosine kinases [38-43].

Due to this important structural role of the DFG-motif, the subsequent analysis focused on the conformation of the respective residues in Hck and Hck*. Figure 7 shows the analysis of the 
backbone angles of the DFG motif and the N-terminally adjacent amino acid A403 during the MD simulations of the inhibited (Fig. 7 a-d) and uninhibited (Fig. 7 e-h) kinase.

No significant changes of the torsion angles $\varphi$ and $\psi$ were detected in the PP1-bound kinases Hck and Hck* (Fig. 7a-d). This indicates that the inhibitor efficiently fixes the active site conformation regardless of the $\mathrm{SH} 3-\mathrm{SH} 2$ linker sequence present. This rigidity is also consistent with the structural overlay showing that the geometry of the kinase domain is almost unaffected by the SH3-SH2 linker sequence (Fig. 4).

The analysis of the torsion angles of uninhibited wildtype Hck generally shows no major fluctuations (Fig. 7 e-h; black curves) and the angles are very similar to the inhibited kinases (Fig. 7 a-d). In contrast, the respective segment of Hck* adopts an alternative backbone geometry during the simulation (Fig. 7 e-h; red curves). After 0.3 ns a correlated change is detected for the neighboring amino acids $\mathrm{A} 403(\psi)$ and D404 $(\varphi)$. Correlated changes of the backbone angles are observed for the amino acids D404( $\psi), \mathrm{F} 405(\varphi, \psi)$, and G406( $\varphi)$ after approximately $4 \mathrm{~ns}$. For the remaining simulation time these novel $\varphi / \psi$ combinations remain remarkably stable and only minor fluctuations are detected.

\section{Comparison of the active site conformation to that of other inactive SFKs}

The conformation of the activation loop detected in our simulations was compared to that of other SFKs. At least two distinct stable conformations of this segment are observed in inactive kinases, which differ in the backbone conformation of the DFG-motif. These conformations were termed "DFG-in" and "DFG-out", respectively [38].

All starting structures of the present simulations correspond to the "DFG-in" conformation, which is also retained in the simulations of PP1-bound Hck/Hck* as well as in the simulation of uninhibited wildtype Hck. For the uninhibited Hck*, a distinct conformation forms during the MD simulation and the backbone conformation formed by Asp404 is somewhat reminiscent of the "DFG-out" conformation, which is also characterized by a negative Asp404 $\varphi$ angle of approximately -130 to -150 degree. For residues F405 and G406 the conformation of $\mathrm{Hck}^{*}$, however, is clearly distinct from the DFG-out conformation previously observed in inactive c-Src and Lck [42, 43]. One might speculate that the Hck* backbone conformation either represents a novel stable topology or that the 30-ns structure 
reflects a local energy minimum which is formed during a transition from the DFG-in to the DFG-out conformation.

Since our results indicate that mutations of the SH3-SH2 linker affect the active site geometry of Hck, we have checked the literature, whether remote effects of mutations on the active site conformation have already been reported for other SFKs in the past. An interesting example comes from c-Src, which can adopt either a DFG-in or a DFG-out conformation. For wildtype c-Src, the DFG-out conformation is energetically quite unfavourable [44, 43]. This is reflected in the low affinity of c-Src for the drug imatinib, which exclusively binds the DFGout conformation. The structural origin for the low imatinib binding affinity of c-Src was also investigated by mutational studies [43]. The strongest increase in drug sensitivity was observed for three mutations (W260A, F405A, L407G), which destabilize the DFG-in conformation of c-Src. While F405 and L407 are located close to the imatinib-binding site, W260 is located in the N-lobe approximately $15 \AA$ apart from the ligand indicating that longrange effects actually affect the drug binding properties.

Our present results further support the importance of long-range effects by demonstrating that the inactive conformation of the kinase domain cannot only be destabilized by mutations in the kinase domain itself, but also by mutations within the regulatory domains. The SH3-SH2 domain linker mutations studied here are more than $30 \AA$ apart from the active site (Fig. 1b, Fig. 4). The sequence of the SH3-SH2 domain linker thus exerts a remote effect on the active site geometry and might therefore play a role in modulating the structure of the inactive kinase or for the fine-tuning of the activation process itself.

\section{Acknowledgments}

The authors thank Pia Rücker and Dr. Holger Dinkel for fruitful discussions, and A. Jens Meiselbach-Wilke for critically reading the manuscript. This work was supported by grants from the Deutsche Forschungsgemeinschaft. 


\section{References}

1. Thomas SM, Brugge JS (1997) Cellular functions regulated by src family kinases. Annu Rev Cell Dev Biol 13:513-609

2. Blume-Jensen P, Hunter T (2001) Oncogenic kinase signalling. Nature 411:355-365

3. Brown MT, Cooper JA (1996) Regulation, substrates and functions of src. Biochim Biophys Acta 1287:121-149

4. Tatosyan AG, Mizenina OA (2000) Kinases of the src family: Structure and functions. Biochemistry (Mosc) 65:49-58

5. Engen JR, Wales TE, Hochrein JM, Meyn MA $3^{\text {rd }}$, Banu Ozkan S, Bahar I, Smithgall TE (2008) Structure and dynamic regulation of src-family kinases. Cell Mol Life Sci 65:3058-3073

6. Williams JC, Weijland A, Gonfloni S, Thompson A, Courtneidge SA, Superti-Furga G, Wierenga RK (1997) The 2.35 a crystal structure of the inactivated form of chicken src: A dynamic molecule with multiple regulatory interactions. J Mol Biol 274:757-775

7. Xu W, Harrison SC, Eck MJ (1997) Three-dimensional structure of the tyrosine kinase csrc. Nature 385:595-602

8. Xu W, Doshi A, Lei M, Eck MJ, Harrison SC (1999) Crystal structures of c-src reveal features of its autoinhibitory mechanism. Mol Cell 3:629-638

9. Sicheri F, Moarefi I, Kuriyan J (1997) Crystal structure of the src family tyrosine kinase hck. Nature 385:602-609

10. Schindler T, Sicheri F, Pico A, Gazit A, Levitzki A, Kuriyan J (1999) Crystal structure of hck in complex with a src family-selective tyrosine kinase inhibitor. Mol Cell 3:639-648

11. Lerner EC, Smithgall TE (2002) Sh3-dependent stimulation of src-family kinase autophosphorylation without tail release from the sh2 domain in vivo. Nat Struct Biol 9:365-369

12. Moarefi I, LaFevre-Bernt M, Sicheri F, Huse M, Lee CH, Kuriyan J, Miller WT (1997) Activation of the src-family tyrosine kinase hck by sh3 domain displacement. Nature $385: 650-653$

13. Cowan-Jacob SW (2006) Structural biology of protein tyrosine kinases. Cell Mol Life Sci 63:2608-2625

14. Hubbard SR, Till JH (2000) Protein tyrosine kinase structure and function. Annu Rev Biochem 69:373-398 
15. Yamaguchi H, Hendrickson WA (1996) Structural basis for activation of human lymphocyte kinase lck upon tyrosine phosphorylation. Nature 384:484-489

16. Harrison SC (2003) Variation on an src-like theme. Cell 112:737-740

17. Young MA, Gonfloni S, Superti-Furga G, Roux B, Kuriyan J (2001) Dynamic coupling between the sh2 and sh3 domains of c-src and hck underlies their inactivation by cterminal tyrosine phosphorylation. Cell 105:115-126

18. Arold ST, Ulmer TS, Mulhern TD, Werner JM, Ladbury JE, Campbell ID, Noble ME (2001) The role of the src homology 3-src homology 2 interface in the regulation of src kinases. The Journal of biological chemistry 276:17199-17205

19. Hofmann G, Schweimer K, Kiessling A, Hofinger E, Bauer F, Hoffmann S, Rösch P, Campbell ID, Werner JM, Sticht H (2005) Binding, domain orientation, and dynamics of the lck sh3-sh2 domain pair and comparison with other src-family kinases. Biochemistry 44:13043-13050

20. Tripos (1991-2002) Sybyl 6.9, release 7.0a. St. Louis, Missouri, USA

21. Thomson MA (2004) Arguslab 4.0.1. Planaria Software LLC, Seattle, WA, USA

22. Frisch MJ, Trucks GW, Schlegel HB, Scuseria GE, Robb MA, Cheeseman JR, Montgomery JA, Jr., Vreven T, Kudin KN, Burant JC, Millam JM, Iyengar SS, Tomasi J, Barone V, Mennucci B, Cossi M, Scalmani G, Rega N, Petersson GA, Nakatsuji H, Hada M, Ehara M, Toyota K, Fukuda R, Hasegawa J, Ishida M, Nakajima T, Honda Y, Kitao O, Nakai H, Klene M, Li X, Knox JE, Hratchian HP, Cross JB, Bakken V, Adamo C, Jaramillo J, Gomperts R, Stratmann RE, Yazyev O, Austin AJ, Cammi R, Pomelli C, Ochterski JW, Ayala PY, Morokuma K, Voth GA, Salvador P, Dannenberg JJ, Zakrzewski VG, Dapprich S, Daniels AD, Strain MC, Farkas O, Malick DK, Rabuck AD, Raghavachari K, Foresman JB, Ortiz JV, Cui Q, Baboul AG, Clifford S, Cioslowski J, Stefanov BB, Liu G, Liashenko A, Piskorz P, Komaromi I, Martin RL, Fox DJ, Keith T, Al-Laham MA, Peng CY, Nanayakkara A, Challacombe M, Gill PMW, Johnson B, Chen W, Wong MW, Gonzalez C, Pople JA (2004) Gaussian03. Gaussian Inc, Wallingford, USA

23. Bayly CI, Cieplak P, Cornell WD, Kollman PA (1993) A well-behaved electrostatic potential based method using charge restraints for deriving atomic charges: The resp model. J Phys Chem 97:10269-10280

24. Cornell WD, Cieplak P, Bayly CI, Kollman PA (1993) Application of resp charges to calculate conformational energies, hydrogen bond energies and free energies of solvation. J Am Chem Soc 115:9620-9631 
25. Case DA, Darden TA, III TEC, Simmerling CL, Wang J, Duke RE, Luo R, Merz KM, Wang B, Pearlman DA, Crowley M, Brozell S, Tsui V, Gohlke H, Mongan J, Hornak V, Cui G, Beroza P, Schafmeister C, Caldwell JW, Ross WS, Kollman PA (2004) Amber 8. University of California, San Francisco, USA

26. Pearlman DA, Case DA, Caldwell JW, Ross WS, Cheatham TE, 3rd, DeBolt S, Ferguson D, Seibel G, Kollman P (1995) Amber, a package of computer programs for applying molecular mechanics, normal mode analysis, molecular dynamics and free energy calculations to simulate the structural and energetic properties of molecules. Comp Phys Commun 91:1-41

27. Cheatham TE, 3rd, Cieplak P, Kollman PA (1999) A modified version of the cornell et al. Force field with improved sugar pucker phases and helical repeat. J Biomol Struct Dyn $16: 845-862$

28. Cornell WD, Cieplak P, Bayly CI, Gould IR, Merz KMJ, Ferguson DM, Spellmeyer DC, Fox T, Caldwell JW, Kollman PA (1995) A second generation force fiel for the simulaton of proteins, nucleic acids and organic molecules. J Am Chem Soc 117:5179-5197

29. Wang J, Wolf RM, Caldwell JW, Kollman PA, Case DA (2004) Development and testing of a general amber force field. J Comput Chem 25:1157-1174

30. Homeyer N, Horn AH, Lanig H, Sticht H (2006) Amber force-field parameters for phosphorylated amino acids in different protonation states: Phosphoserine, phosphothreonine, phosphotyrosine, and phosphohistidine. J Mol Model 12:281-289

31. Jorgensen WL, Chandrasekhar J, Madura JD, Impey RW, Klein ML (1983) Comparison of simple potential functions for simulating liquid water. J Chem Phys 79:926-935

32. Wartha F, Horn AHC, Meiselbach H, Sticht H (2005) Molecular dynamics simulations of hiv-1 protease suggest different mechanisms contributing to drug resistance. Journal of Chemical Theory and Computation 1:315-324

33. Berendsen HJC, Postma JPM, van Gunsteren WF, DiNola A, Haak JR (1984) Molecular dynamics with coupling to an external bath. J Chem Phys 81:3684-3690

34. Darden TA, York DM, Pedersen LG (1993) Particle mesh ewald. An n.Log(n) method for ewald sums in large systems. J Chem Phys 98:10089-10092

35. Ryckaert JP, Ciccotti G, Berendsen HJC (1977) Numerical integration of the cartesian equations of motion of a system with constraints: Molecular dynamics of n-alkanes. $J$ Comput Phys 23:327-341

36. Humphrey W, Dalke A, Schulten K (1996) Vmd -- visual molecular dynamics. J Mol Graph 14:33-38 
37. Accelrys (2005) Ds viewerpro suite 6.0 (computer program). San Diego, CA, USA

38. Levinson NM, Kuchment O, Shen K, Young MA, Koldobskiy M, Karplus M, Cole PA, Kuriyan J (2006) A src-like inactive conformation in the abl tyrosine kinase domain. PLoS Biol 4:e144

39. Nagar B, Bornmann WG, Pellicena P, Schindler T, Veach DR, Miller WT, Clarkson B, Kuriyan J (2002) Crystal structures of the kinase domain of c-abl in complex with the small molecule inhibitors pd173955 and imatinib (sti-571). Cancer Res 62:4236-4243

40. Nagar B, Hantschel O, Young MA, Scheffzek K, Veach D, Bornmann W, Clarkson B, Superti-Furga G, Kuriyan J (2003) Structural basis for the autoinhibition of c-abl tyrosine kinase. Cell 112:859-871

41. Dar AC, Lopez MS, Shokat KM (2008) Small molecule recognition of c-src via the imatinib-binding conformation. Chem Biol 15:1015-1022

42. Jacobs MD, Caron PR, Hare BJ (2008) Classifying protein kinase structures guides use of ligand-selectivity profiles to predict inactive conformations: Structure of lck/imatinib complex. Proteins 70:1451-1460

43. Seeliger MA, Nagar B, Frank F, Cao X, Henderson MN, Kuriyan J (2007) C-src binds to the cancer drug imatinib with an inactive abl/c-kit conformation and a distributed thermodynamic penalty. Structure 15:299-311

44. Aleksandrov A, Simonson T (2010) Molecular dynamics simulations show that conformational selection governs the binding preferences of imatinib for several tyrosine kinases. J Biol Chem 285:13807-13815 


\section{Figure captions}

Fig. 1 (a) Structures of the linker between regulatory domains from the Hck kinase (left), and Lck kinase (right). (b) Overlay of the crystal structure of the Hck kinase (orange, 1QCF) in complex with the inhibitor PP1 (blue), and the Hck* kinase (grey)

Fig. 2 Distance between the center-of-mass of the distinct domains of the PP1-inhibited kinase as a function of simulation time

Left panel: distance between (a) SH3 and N-lobe, (b) N-lobe and C-lobe of the catalytic domain; (c) SH2 and C-lobe, and (d) between the regulatory domains. Black: wildtype Hck; red: Hck* Right panel: a schematic representation of Hck showing the analyzed distances

Fig. 3 Distance between amino acids A403 of the activation segment and S142 located in the SH3-SH2 linker. Black: wildtype Hck kinase; red: Hck*kinase

Fig. 4 Structural changes of PP1-bound Hck and Hck*

(a) The final structure of Hck (black) resulting from the MD simulation is superimposed on the starting structure (gray). The inhibitor PP1 is shown in green space-filled presentation. (b) Same type of overlay for the final Hck* structure (red). Blue arrows highlight the following structural changes compared to the starting structure: Displacement of the SH3 domain, motion of the SH3-SH2 domain linker, and $\alpha \mathrm{B}$-helix rotation in the $\mathrm{SH} 2$ domain

Fig. 5 Distance between the center-of-mass of the distinct domains of the kinase without inhibitor PP1 as a function of simulation time

Distance between (a) SH3 and N-lobe, (b) N-lobe and C-lobe of the catalytic domains; (c) SH2 and C-lobe, and (d) between the regulatory domains. Black: wildtype Hck; red: Hck*. See Fig. 2 (right panel) for a schematic presentation of the analyzed distances

Fig. 6 Structural changes of uninhibited Hck and Hck* 
(a) The final structure of Hck (black) resulting from the MD simulation is superimposed in the starting structure (gray). (b) Same type of overlay for the final Hck* structure (red)

Fig. 7 Torsional angles of the DFG motif $\varphi / \psi$-angles for the PP1-inhibited kinase are shown in a-d, and for the kinase without inhibitor in e-h. Black: wildtype Hck kinase; red: Hck*kinase 
a

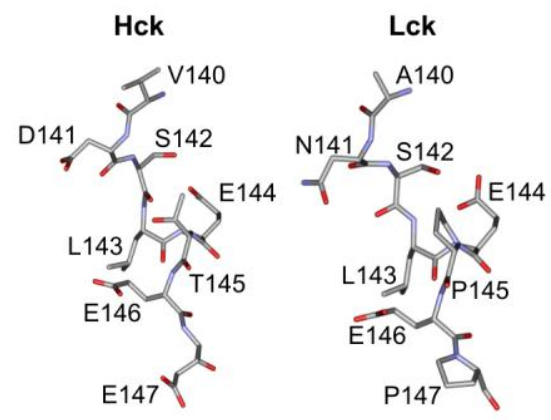

SH3 - SH2 linker
$\mathrm{SH} 2$ - kinase linker

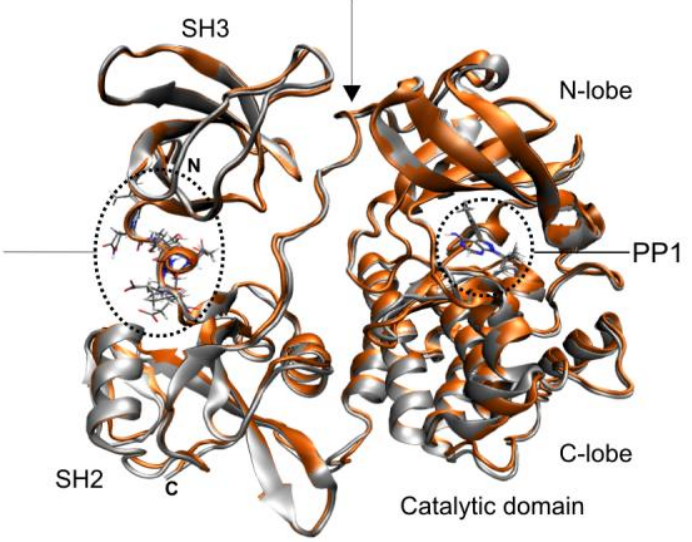


a
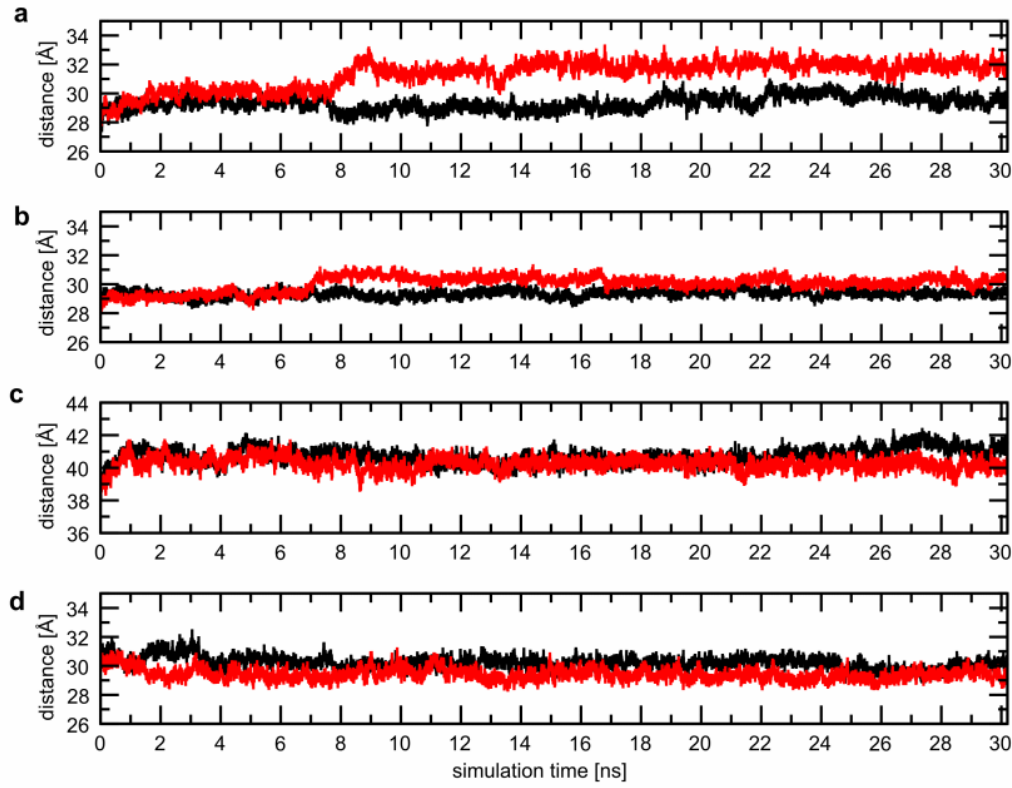

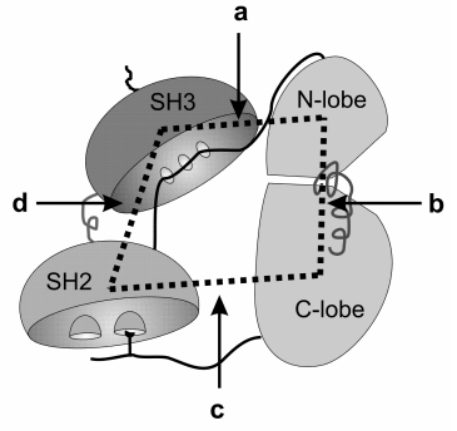




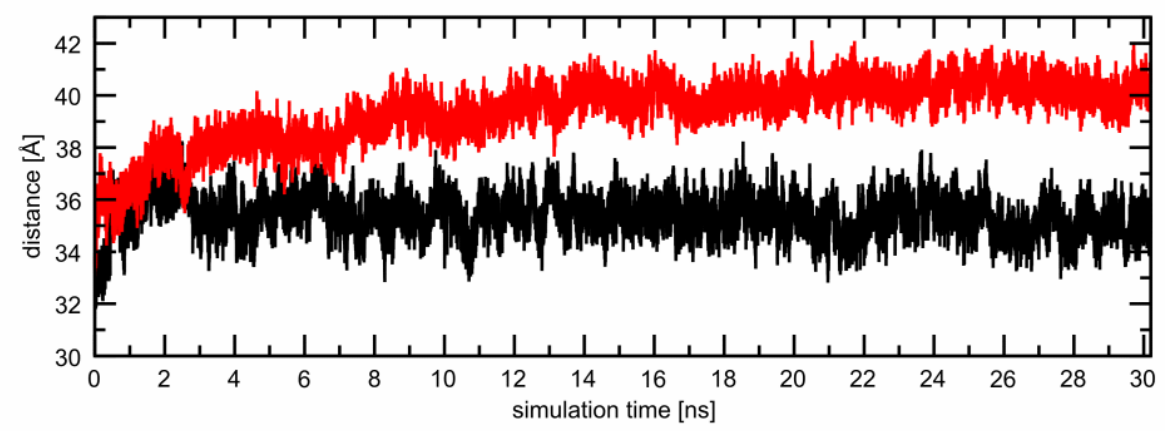



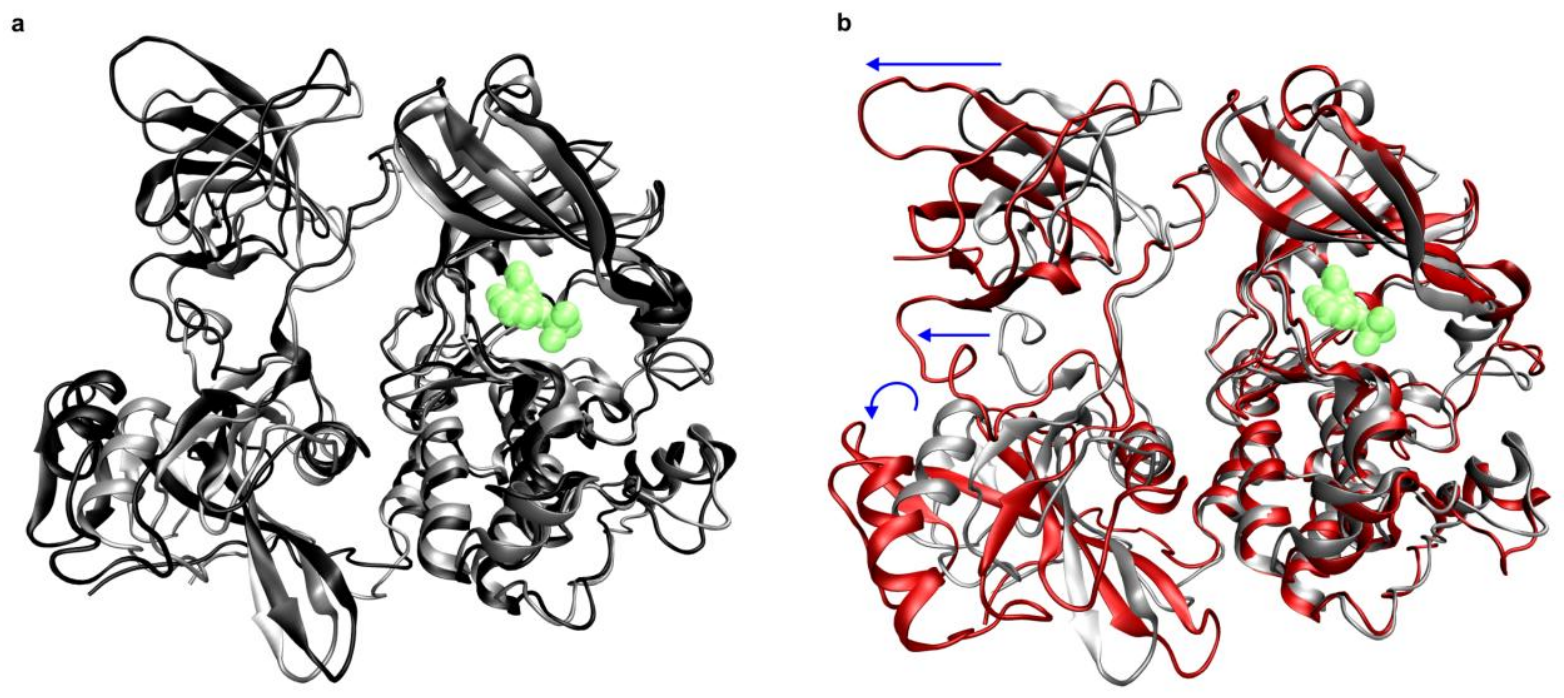
a
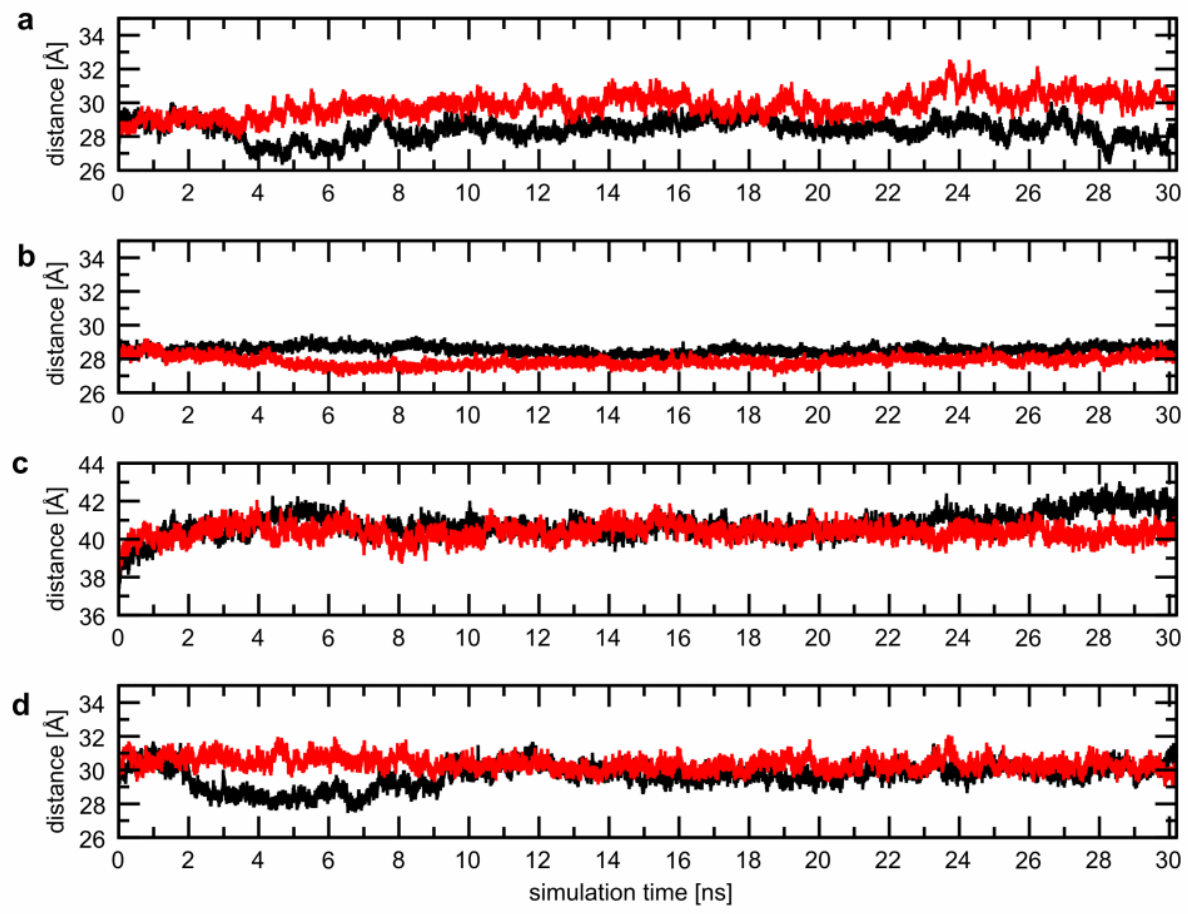

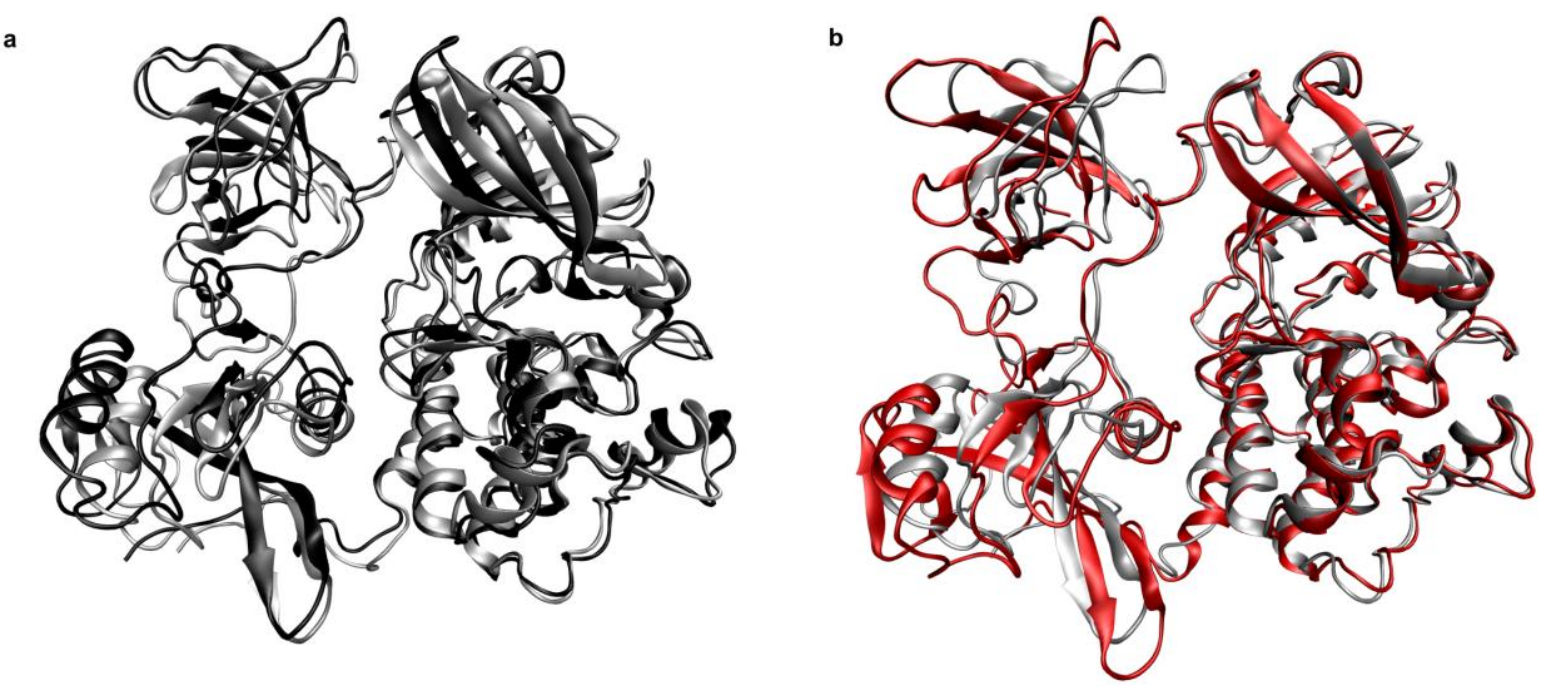


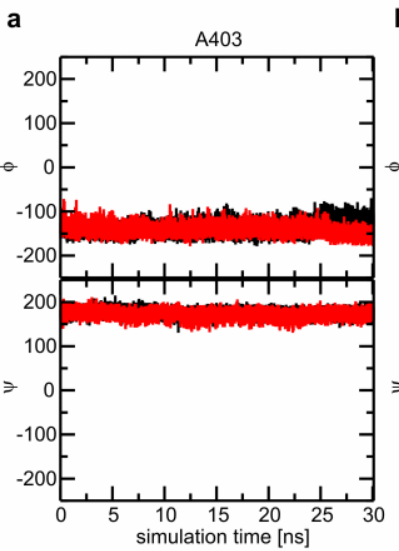

e

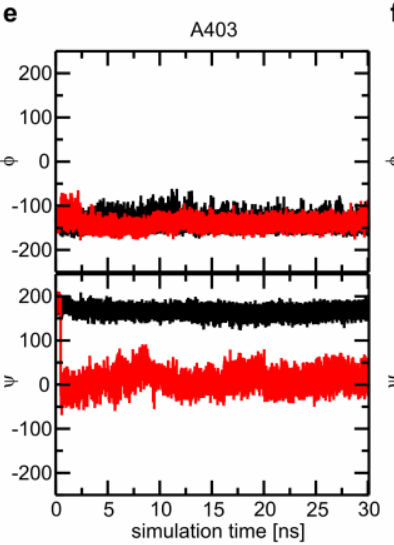

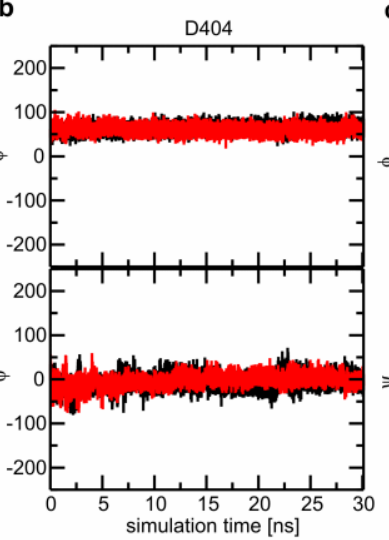

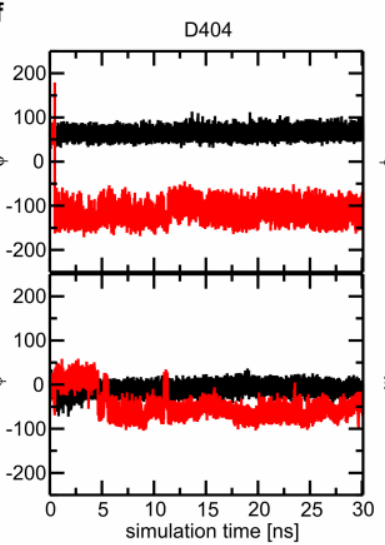

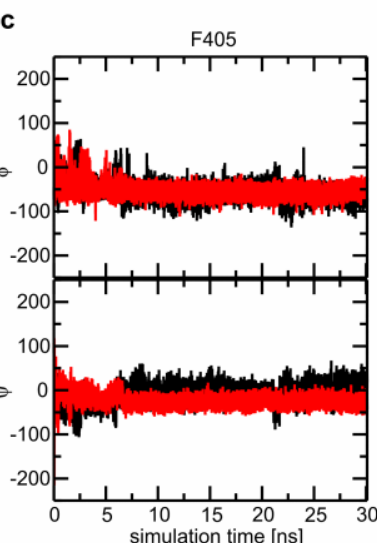

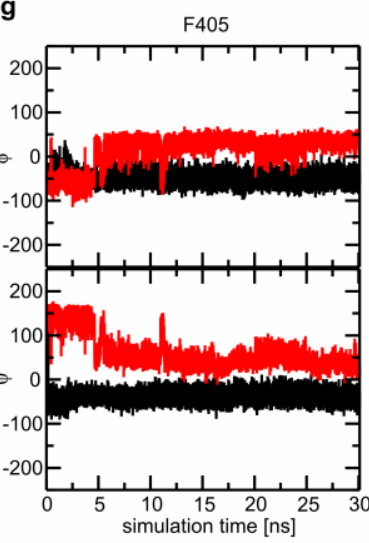

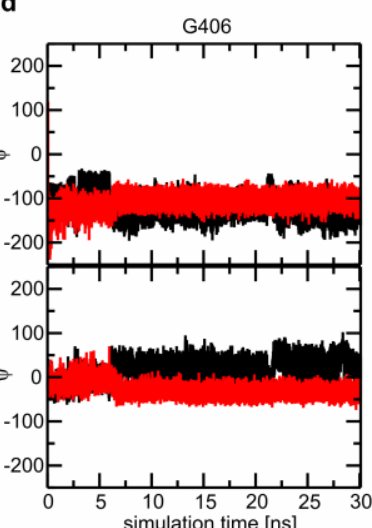

h

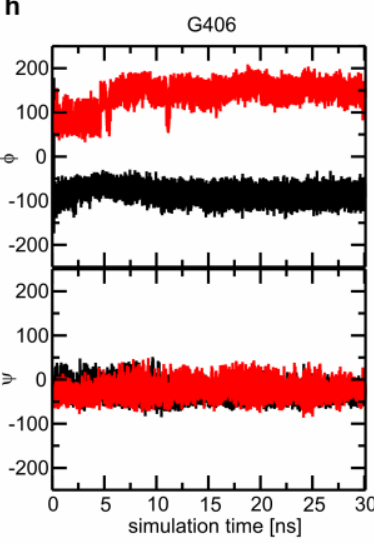

